\title{
On the use of ocean color remote sensing to measure the transport of dissolved organic carbon by the Mississippi River Plume
}

\author{
Carlos E. Del Castillo ${ }^{1}$ \\ Richard L. Miller ${ }^{2}$
}

\begin{abstract}
We investigated the use of ocean color remote sensing to measure transport of dissolved organic carbon (DOC) by the Mississippi River to the Gulf of Mexico. From 2000 to 2005 we recorded surface measurements of DOC, colored dissolved organic matter (CDOM), salinity, and water-leaving radiances during five cruises to the Mississippi River Plume. These measurements were used to develop empirical relationships to derive CDOM, DOC, and salinity from monthly composites of SeaWiFS imagery collected from 1998 through 2005. We used river flow data and a two-end-member mixing model to derive DOC concentrations in the river end-member, river flow, and DOC transport using remote sensing data. We compared our remote sensing estimates of river flow and DOC transport with data collected by the United States Geological Survey (USGS) from 1998 through 2005. Our remote sensing estimates of river flow and DOC transport correlated well $\left(\mathrm{r}^{2} \sim 0.70\right)$ with the USGS data. Our remote sensing estimates and USGS field data showed low variability in DOC concentrations in the river end-member (7-11\%), and high seasonal variability in river flow $(\sim 50 \%)$. Therefore, changes in river flow control the variability in DOC transport, indicating that the remote sensing estimate of river flow is the most critical element of our DOC transport measurement. We concluded that it is possible to use this method to estimate DOC transport by other large rivers if there are data on the relationship between CDOM, DOC, and salinity in the river plume.
\end{abstract}

\section{Introduction}

Large rivers can transport significant amounts of carbon to the ocean. Dissolved organic carbon (DOC), a large component of the riverine carbon pool, can be degraded to $\mathrm{CO}_{2}$ and $\mathrm{CO}$ by respiration and photodegradation. Therefore, the quantification of carbon transport by large rivers is needed to reduce the uncertainties in land-ocean carbon fluxes.

Some rivers, like the Mississippi, are well studied and instrumented, and have highquality data sets that span over a decade. Unfortunately, other large rivers are not as well studied, or in many cases, national data sharing policies prevent easy access to available data. In these cases, satellite remote sensing data, particularly from NASA satellites, are the only data sets readily available. The longevity and success of sensors like the Sea-Viewing Wide Field-ofView Sensor (SeaWiFS) and the Moderate Resolution Imaging Spectroradiometer (MODIS), and the possible extension of similar measurements by the Visible Infrared Imager Radiometer Suite (VIIRS) offer the possibility of multi-decadal studies of land-ocean interactions in river plumes.

There are well-known complications to the use of ocean color remote sensing, and its application in optically complex coastal waters impacted by large river plumes can be particularly difficult. In this manuscript we discuss the development of a method to measure

\footnotetext{
${ }^{1}$ The Johns Hopkins University, Applied Physics Laboratory, Laurel, Maryland, USA.

${ }^{2}$ National Aeronautics and Space Administration, Stennis Space Center, Mississippi, USA
} 
DOC transport by the Mississippi River and document changes in carbon transport during the last 10 years.

\section{Theory}

Concentrations of DOC cannot be measured directly using ocean color sensors because not all the organic carbon is colored. However, colored dissolved organic matter (CDOM), a large component of the dissolved carbon pool, can be observed from space. If there is a good correlation between DOC and CDOM, then it is feasible to estimate DOC in the river plume using ocean color remote sensing. Carbon concentration in the river plume is not, however, a measurement of carbon transport. To estimate carbon transport, we must know the concentration of DOC in the river end-member and the river flow. To truly estimate carbon transport remotely, both measurements should be derived from remote sensing data. If one can derive good empirical relationship between DOC and CDOM, CDOM and salinity, and salinity and river flow, is then possible to estimate DOC transport using exclusively ocean color remote sensing. Figure 1 illustrates this approach.

The success of this approach depends on four conditions. First, DOC and CDOM must behave conservatively in the study site; second, the relationship between CDOM and DOC in the river end-member should remain constant; third, one should be able to derive CDOM from satellite ocean color measurements; forth, salinity in the study area should correlate with river flow. In the following sections we show how these conditions were met.

Data from this and previous studies showed that CDOM and DOC behaved conservatively in the Mississippi River Plume (Figure 2). Changes in conservative behavior can be caused by phodegradation, biodegradation, production, and flocculation. However, several studies have shown that these have little or negligible effects in low salinity waters of river plumes due to the preponderance of riverine CDOM (Mantoura and Woodward, 1983; Del Castillo et al., 1999, 2000, 2001; Blough and Del Vecchio, 2002; Del Vecchio and Blough 2002; and others) Wright (2005), studied the relationship between CDOM and DOC in waters of the Mississippi River proper during a 4-year time series that ended abruptly with Hurricane Katrina. She found that DOC and CDOM co-vary significantly. We cannot claim that this relationship remained constant over the period covered in this manuscript, but there are no compelling reasons to believe that it has not.

Various researchers have worked on the problem of estimating CDOM using ocean color with various levels of success (Carder et al., 1999; Siegel et al., 2002; Lee et al., 1994; Hoge et al., 1995, 2001; Kahru and Mitchell, 2001; Johannessen et al., 2002; Del Castillo, 2005 to cite a few). These studies showed that it is possible to estimate CDOM from ocean color data with accuracies similar or better than those obtained in estimates of chlorophyll. Trying to estimate river flow using ocean color remote sensing is problematic because the success of this approach depends on a series of intermediate relationships, each of which has its own errors and uncertainties. However, the driving relationships are robust: CDOM is a good salinity tracer in river plumes (Figure $2 \mathrm{~b}$ ), and the salinity of the water close to the mouth of the river should change as a function of the river flow. The following sections show the success of this approach.

We chose a priori the ratio of $510 \mathrm{~nm}$ to $670 \mathrm{~nm}(R)$ as a good index of CDOM abundance in the river plume, because in low-salinity river plume waters, most of the light attenuation is controlled by CDOM (Del Castillo et al., 1999; De'Sa et al., 2006). CDOM does not absorb strongly at $660 \mathrm{~nm}$, but riverine CDOM still shows significant absorption at $510 \mathrm{~nm}$, 
whereas chlorophyll does not. Therefore, this ratio, with $670 \mathrm{~nm}$ as a pivot point, should be sensitive to changes in CDOM, and not so much to changes in chlorophyll light absorption. Clearly, we expect that an algorithm based on this relationship should only work well in highCDOM waters, because, at higher salinities, dilution with seawater makes the absorption of $\mathrm{CDOM}$ at $510 \mathrm{~nm}$ negligible. This algorithm should not work either in areas with high-Chl concentrations. However, we intended to use it in waters very close to the mouth of the river, where CDOM dominates the optical properties of the water column. Interestingly, Kahru and Mitchell (2001) proposed a similar pivot point approach, but with an inverse rationale. Their assumption was that absorption of CDOM is very low in the 500 to $520 \mathrm{~nm}$ range, and used 443 $\mathrm{nm}$ as an index of CDOM and $510 \mathrm{~nm}$ as the pivot point. Although this assumption is correct for their study site, it does not work for our data set, because there is still CDOM absorption at 443 $\mathrm{nm}$ in riverine CDOM. We investigated the 412/670 and 443/670 ratios and found that the variability in reflectance was due to CDOM absorption in the blue wavelengths (as in Kahru and Mitchell, 2001), and the ratios correlated well with CDOM. However, we decided to analyze the satellite imagery using only the 510/670 ratio to limit the problems with atmospheric corrections in the blue wavelengths.

\section{Study Site}

The Mississippi River is particularly well suited for this work, because a large portion of the lower Mississippi is levied, limiting land-river interactions at the bird-foot delta. Also most of its flow comes out of South West Pass, making a well-defined plume; tidal influences are small; and there are excellent data sets from the United States Geological Survey (USGS) to validate the results of the study. In this work we show field data on CDOM, DOC, and salinity collected along the Mississippi River Plume and offshore waters of the Gulf of Mexico during several cruises between 2000 and 2005. However, all work pertaining to algorithm development, remote sensing data, and DOC transport calculations was done using data from a small area directly off Southwest Pass (Figure 3). Our choice of site was driven by the need to relate what we measured in the plume to the carbon that is being transported by the river. This small study area was close enough to the mouth of the river to limit the effect of river plume processes (other than dilution) upon organic matter and maximize the effect of river flow upon salinity, but far enough from land to avoid contamination on the remote sensing signal.

\section{Methods}

The water samples and optical measurements used for algorithm development were collected during three cruises on board the R/V Acadiana (58') and two cruises on board the R/V Pelican (116') both from the Louisiana Universities Marine Consortium between 2000 and 2004. Cruises on the R/V Acadiana were designed specifically for this study, and we collected samples only off Southwest Pass and a few miles up-river. The R/V Pelican cruises were sponsored by the NASA-EPSCoR Program and covered a larger area in the Gulf of Mexico.

Optical Measurements- We recorded above-water remote sensing reflectance measurements at 1$\mathrm{nm}$ interval between 400 and $825 \mathrm{~nm}$ using a GER 1500 (Geophysical Environmental Research) fiber optic spectroradiometer. We followed the protocol of Mueller and Austin (1995). Our GER is equipped with an $\sim 2-\mathrm{m}$ long, 512-channel fiber optic cable encased in a stainless steel tube. 
This allows us to record measurements $\sim 2 \mathrm{~m}$ away from the side of the research vessel, reducing its influence upon our measurements. Above-water remote sensing reflectance, $R_{r s}(\lambda$,), was derived according to Mueller and Austin (1995). Briefly, using the GER 1500 we recorded radiance spectra from surface waters $\left(L_{\lambda, \text { sea }}\right)$, followed by measurements of sky radiance $\left(L_{\lambda, \text { sky }}\right)$, and radiance from a $10 \%$-reference Spectralon placard (Labsphere). All measurements were taken, at least, in triplicates. $R_{r s}(\lambda$,$) was calculated as$

$$
R_{r s}(\lambda,)=\left(L_{\lambda, \text { sea }}-\rho(\theta) L_{\lambda, s k y}\right) /\left(\pi L_{p l} / \rho_{p l}\right)-\text { residual }_{750 \mathrm{~nm}},
$$

where $\rho$ is the Fresnel reflectance, $\theta$ is the viewing angle $\left(30^{\circ}\right), \rho_{p l}$ is the reflectance of the Spectralon, and the residual ${ }_{750 \mathrm{~mm}}$ is the signal at $750 \mathrm{~nm}$ that is subtracted to remove any residual reflected radiance from the sky.

We used the triplicate $R_{r s}$ spectra for each station to calculate an average spectrum and the standard deviation and coefficient of variation $(C V)$ amongst estimates of $R_{r s}$ at 510 and 670 $\mathrm{nm}$. We also analyzed the variability of $510 / 670(R)$ within the triplicates obtained at each station. We decided a priori that stations with $C V$ larger than $15 \%$ were to be eliminated from the data set. We also excluded stations with salinities of 30 or higher. High- salinity stations were excluded, because our approach should only work in waters where riverine CDOM is the main light absorber and conservative behavior is preponderant. As stated before, several studies showed that these conditions are not met in river plume waters with salinities higher than 30 (Blough et al., 1993; Del Castillo et al., 1999). Finally, stations with $R$ higher than 2.4 were also eliminated, because previous results indicated that $R$ values higher than $\sim 2.4$ return unrealistic values of ag412 (see figure 15 in Del Castillo, 2005); that is, lower than $0.046 \mathrm{~m}^{-1}$, which is the detection limit of a dual-beam spectrophotometer equipped with $10-\mathrm{cm}$ cells. It turns out that most samples with high $R$ also had high salinity or high $\mathrm{CV}$, or both, although few stations with high salinity and $R$ values exhibited very clean spectra. We were left with 20 acceptable spectra from 46 collected -17 had salinities higher than 30 .

Water Sampling and Analysis- Water samples for CDOM and DOC analyses were collected simultaneously with the optical measurements. Our sampling device was a glass bottle enclosed in a weighed rig suspended $\sim 10 \mathrm{~cm}$ from a float. The rig was attached to a Dacron line via a Sampo swivel, and the line was kept coiled in a fishing yo-yo. This sampling apparatus, which was christened "The Thingy", was thrown overboard away from the boat and recovered after the sampling bottle was full. The Thingy allowed us to easily sample very close to the surface - an important feature in plume work - and limited contamination from the vessel. Filtration for CDOM and DOC was done by gravity under low-intensity red lights using GF/F filters mounted on an all-stainless steel apparatus. Filters and sample bottles were ashed $\left(450^{\circ} \mathrm{C}-12\right.$ hours), and all other components were meticulously cleaned with acetonitrile and Nanopure water. The filtration system was flushed with sample $(\sim 20 \mathrm{ml})$ before collecting the CDOM and DOC subsamples. DOC samples were placed in ashed vials with caps that were lined with clean Teflon septa. The vials were pre-loaded with enough phosphoric acid to lower the sample $\mathrm{pH}$ below 2 . CDOM samples were stored in ashed amber-colored bottles. All samples were stored refrigerated until analysis.

Absorption Spectroscopy- Absorption spectra of filtered samples were obtained between 250 and $700 \mathrm{~nm}$ at 1-nm intervals using a Perkin Elmer Lamda-18 double-beam spectrophotometer equipped with matching $10-\mathrm{cm}$ quartz cells. Nanopure water was used in the 
reference cell. The absorption coefficients, $a(\lambda)$, were calculated using: $a(\lambda)=2.303 A(\lambda) / l$, where $A$ is the absorbance $\left(\log _{10} \mathrm{I}_{0} / \mathrm{I}\right)$ and $l$ is the pathlength in meters. Absorption at $412 \mathrm{~nm}$ was used as an index of CDOM concentration and will be referred to as $a_{g} 412$.

Carbon Concentrations- DOC concentrations were determined using the hightemperature catalysis method with an MQ1001 carbon analyzer (Qian and Mopper, 1996). The instrument was equipped with a quartz catalyst and a Li-Cor $6252 \mathrm{CO}_{2}$ detector. Potassium hydrogen phthalate was used as the standards. An instrument blank was determined daily by reinjection of post-column condensation water that is expected to be virtually carbon-free. The stability of the instrument was monitored by repeated injection of a standard $\left(1.2 \mathrm{mg}^{-1}\right)$ every 10 samples and full standard sets $\left(0.60,0.90,1.20,1.50,3.00\right.$, and $\left.6.00 \mathrm{mg}^{-1}\right)$ before and after each sample run.

Satellite Image Processing- We downloaded daily 1-km SeaWiFS L2B imagery of the Mississippi River Plume area (Figure 3) from the NASA DAAC. We used imagery from January 1998 through December 2005 and produced L3 monthly composites using SEADAS software. We decided to analyze monthly composites to limit the effect of cloud cover. From the monthly composites we extracted the normalized water-leaving radiances data for all ocean color bands from a $15 \times 15$ pixel square typically centered at $28.8^{\circ},-89.5^{\circ}$. This area is strongly affected by the Mississippi River Plume and was sampled during the Acadiana cruises. From this large pixel box, we used the radiance values averaged from a $3 \times 3$ pixel square centered at the same coordinates. However, during periods of low flow, we used the northernmost pixel squares within our $15 \times 15$ pixel area, because these were closer to the mouth of the river.

\section{Results}

Algorithm Development- Weather conditions during Acadiana I were exceptional, with flat seas and clear skies. We were able to control well the vessel positioning, avoided white caps and other problems associated with rough seas. Consequently, the water-leaving radiance measurements collected during this cruise are of the best quality we have. The other Acadiana and Pelican cruises were not as pleasant. The relationship between $R$ and ag412 for measurements collected during Acadiana I was excellent $\left(\mathrm{r}^{2}=0.94\right)$. When data from the other cruises were included, the $r^{2}$ was lower, 0.60 (Figure 4). However, and remarkably, the linear regression lines for Acadiana I, all the cruises, and all cruises minus Acadiana I had slopes and elevations that were not statistically different to a high level of significance (Student's $t$ test Zar, 1996). This result suggests that the variability around the regression line added by the nonAcadiana I data was probably caused by the less-than-ideal weather conditions. However, the errors were distributed in such a way that the underlying relationship between $a g 412$ and $R$ was preserved. Although the inclusion of all data did not significantly change the equation parameters, we decided to use the best data set of Acadiana I. The best possible fit to the data set was a linear function of the form

$$
a_{g} 412=-0.90 R+2.34,
$$

where $R=\operatorname{Rrs} 510 / \operatorname{Rrs} 670$. The regression coefficient was $0.94, \mathrm{n}=10$. 
We used equation 2 and the empirical relationships between CDOM and DOC, and salinity (data from Figure 2) to develop empirical equations for DOC and salinity in the form of:

$$
\begin{aligned}
& D O C_{P}=-1.41 R+4.9, \text { and } \\
& \text { Salinity }=17.14 R-10.11,
\end{aligned}
$$

where $D O C_{P}$ is the concentration of DOC in the river plume in $\mathrm{mg}^{-1}$.

Remote Sensing Estimate of River Flow- We explored the relationship between river flow and modeled salinity by comparing our monthly salinity estimates obtained from SeaWiFS imagery (equation 4) and river flow data from the USGS (monthly averages of daily measurements from 1998 and 2005). The data showed a remarkable correlation between river flow and modeled salinity (Figure 5A). Because the salinity estimate depends on good satellite retrieval of $a_{g} 412$ and good relationships between salinity and river flow, these results indicate that the underlying assumptions of this project were robust. Therefore, we can compute river flow as

$$
\text { Flow }\left(l s^{-1}\right)=-1.62 \times 10^{7} R+4.43 \times 10^{7} .
$$

Figure 5B shows a comparison between measured river flow and modeled flow obtained from equation 5 .

Remote Sensing Estimates of Carbon Transport and Validation Using USGS Data- To verify the overall effectiveness of our method, we compared our results with data collected by the USGS. Through the excellent National Stream Quality Accounting Network (NASQAN) (http://water.usgs.gov/nasqan/), the USGS has been collecting data on concentrations of several dissolved and particulate components, including DOC, as well as river flow measurements for many rivers in the continental United States of America. Data are available from 1995 and can be downloaded freely from the NASQAN website. The data for DOC typically included one to two measurements per month and associated river flows. There were also a small number of days in which more than one measurement was taken. These samples were collected near St. Francisville, LA., about $400 \mathrm{~km}$ from Southwest Pass. When there was more than one datum per day, or per month, we averaged the values and, with the other data, treated them as monthly DOC concentration for the site. We assumed that the concentration of DOC did not change significantly between St. Francisville and Southwest Pass and have a small data set to support this assumption. We compared USGS DOC data with DOC concentrations from the 16 samples collected in Forth Jackson, LA. ( 410 km from St. Francisville, $\sim 56 \mathrm{~km}$ from Southwest Pass) between July 2001 and March 2005. Our samples and the USGS were collected the same month, not the same day. The average carbon concentrations in our samples and the USGS samples were 3.7 and $3.6 \mathrm{mg} \mathrm{l}^{-1} 1$, respectively $\left(\mathrm{n}=16\right.$, stdev $\left.=0.5 \mathrm{mg} \mathrm{l}^{-1}\right)$. Values ranged from 4.6 to 2.5 $\mathrm{mg}^{-1}$, and in most sample pairs, the difference between the USGS and our measurement was within 1 stdev.

The comparison between our satellite estimates of DOC and the USGS in-situ measurements presented some problems. The satellite measurements originated from monthly composites, whereas most of the USGS data were from one sample per month (few with replicates the same day), and occasionally two sampling dates per month. We studied the

$$
-6-
$$


variability within the USGS data set and found that for days in which two or more measurements were taken, the coefficient of variation $(\mathrm{CV})$ was typically lower than $5 \%$, often $0 \%(\mathrm{n}=17)$, showing excellent precision. We also analyzed the variability between DOC samples collected during different dates within a month. In this case, the $\mathrm{CV}$ within the months varied between 2 and $22 \%$, with most months having a CV over $7 \%$ and an average of $8 \%(n=19)$. We also compared the river flow values recorded simultaneously with the DOC samples with monthly river flow averages. The $\mathrm{CV}$ varied from 1 to $38 \%$ and averaged $8 \%$, but most dates had a $\mathrm{CV}$ higher than $8 \%$. This last comparison was the most closely match to our comparison between remote sensing estimates of DOC and the USGS in-situ measurements; that is, a comparison between a monthly average and a datum within a month. This means that, even if remote sensing estimates of DOC were exact, the natural variability in DOC concentration within a month should result in differences between modeled and measured DOC between 2 and $22 \%$, averaging $8 \%$. This sets a statistical limitation to our comparisons. The other problem related to the timelag between the USGS measurement at St. Francisville and the arrival of the sampled water parcel at Southwest Pass. If we would have used, for example, an average river flow speed of $\sim 3$ knots, several samples collected late during a month would have to be moved to the next month to be compared with our satellite data. During high flows the situation would have become more problematic, for more samples would have to be re-dated. Unfortunately, we were not able to find the needed flow speed data to attempt a lag- time correction.

We applied equation 3 to our monthly averages of satellite imagery to calculate DOC concentration in the $3 \times 3$ pixel square off Southwest Pass. These DOC concentrations corresponded to waters with salinities that varied between $\sim 4$ and 30 . Therefore, we extrapolated these values to the DOC concentrations corresponding to a salinity of $\sim 0$ to represent the river end-member. The concentration of DOC in the river plume resulted from the contribution of riverine and marine DOC. We applied a simple two end-member mixing model to calculate the concentration of DOC in the riverine end-member. We used this model before very successfully when working with several river plumes (Del Castillo et al., 2000). For this case, the model assumed a riverine end-member salinity of 0 , and a marine end-member with salinity of $\sim 35$ and a DOC concentration of $\sim 1.3 \mathrm{mg} \mathrm{l}^{-1}$. We determined the salinity and the DOC concentration of the marine end-member from the empirical relationships and field data collected for this study. We also experimented using other end-member values reported in the literature. These values were within the standard error of our data, and we found that these small variations $(<10 \%)$ in the marine end-member salinity and DOC did not significantly affect our results. River end-member DOC concentrations were calculated as

$$
D O C_{0}=\left(D O C_{P}-\left(\operatorname{sal}_{P} / 35 \times 1.3\right)\right) /\left(1-\left(\operatorname{sal}_{P} / 35\right)\right)
$$

where $D O C_{0}$ and $D O C_{P}$ are the DOC concentrations in the river end-member and river plume in $\mathrm{mg}^{-1}$ respectively, and $s a l_{P}$ is the salinity in the river plume calculated from equation 4 . Values of $D O C_{0}$ were multiplied by the modeled flow obtained from equation 5 to obtain DOC transport. Figure 6 shows a comparison between DOC transport calculated using USGS data and our modeled DOC transport. The results show that our method explained $\sim 70 \%$ of the variability in DOC transport by the Mississippi River. 


\section{Discussion}

We stated that four conditions were needed to measure DOC transport by the Mississippi River using ocean color data. First, DOC and CDOM must behave conservatively in the study site; second, the relationship between CDOM and DOC in the river end-member should remain constant; third, one should be able to derive CDOM from satellite ocean color measurements; forth, salinity in the study area should correlate with river flow. The results shown here indicate that these conditions were met. Conservative behavior of DOC and CDOM, the relationship between DOC and CDOM, as well as the capability to derive CDOM from ocean color has been shown by others. What is particular to this work is the correlation found between river flow and modeled salinity, which allowed us to calculate DOC transport. The correlation between river flow and salinity also indicates that our CDOM algorithm was competent, because the salinities were calculated from measurements of $R$ through the empirical relationship between CDOM and salinity from figure 2 . Our success in explaining close to $70 \%$ of the variability in DOC transport also indicates that the CDOM algorithm was competent, and that the CDOM to DOC relationship was robust, particularly because the DOC transport calculation contained the intermediate steps of calculating $D O C_{0}$, and river flow.

Variability in DOC transport was driven mainly by changes in river flow, not by changes in DOC concentration. The variability in our $D O C_{0}$ estimates was $\sim 5 \%$, and the variability in the USGS measurements was $\sim 11 \%$. The USGS values were expected to have higher variability, because they were mostly single measurements per month, whereas ours were the equivalent of monthly averages. However, the variability in river flow was $\sim 50 \%$. If we would have just used an average value of $D O C_{0}$ of $3.7 \mathrm{mg}^{1}$ for every month and the river flows calculated in our method, we would have gotten a correlation between modeled and measured fluxes with an $\mathrm{r}^{2}$ of 0.68 , and similar equation parameters to those of figure 6B. This indicates that the critical measurement was not $D O C_{0}$, but the retrievals of CDOM from satellite imagery, and the empirical relationships between CDOM and salinity, and salinity and river flow.

The USGS DOC data showed a small, but statistically significant, decline in DOC concentrations in the river. This trend remained even after filtering the data using various methods. Our $D O C_{0}$ estimates did not show this trend. We believe that the trend observed in the USGS data was driven by samples collected after 2003. This was also the period in which we observed the largest discrepancies between our results and the USGS data. These data collected after 2003 have been classified by the USGS as provisional, and although they make the data available, the USGS indicates that these are subject to revision and cautions against publication. Data collected before 2004 are considered reliable for publication..

\section{Conclusions}

Our results showed that it is possible to obtain reasonable estimates of DOC transport by the Mississippi River using exclusively ocean color data. Our simple ratio algorithm and the relationship shown in equation 2 should apply to most river plumes, because it should be independent of the spectral character of CDOM. We are still exploring this issue. However, the relationship between DOC and CDOM, and CDOM and salinity depends on the character of the organic matter and the CDOM concentration of the river end-member, and should be regional. We suggest that the relationship between modeled salinity at the mouth of the river and river flow should be very similar for all rivers, because it is based only on the dilution of riverine 
CDOM in seawater, and the empirical relationship between CDOM and $R$. We are also exploring this question. We concluded that it is possible to remotely estimate DOC transport in most large rivers, if adequate CDOM, DOC, and salinity data from river plumes are available.

Acknowledgments. We thank Vanessa Wright, Callie Hall, Bruce Spiering, and Ingrid GarcíaHansen, who participated in several of the research cruises and helped in the collection of the data presented in this paper. Jorge Corredor, Eurico D'Sa, Julio Morel, and Joe Salisbury provided useful comments and discussion. We also thank the crews of the $\mathrm{R} / \mathrm{V}$ Acadiana, $\mathrm{R} / \mathrm{V}$ Pelican and the personnel of the Louisiana Universities Marine Consortium for their help. We specially thank the National Aeronautics and Space Administration Ocean Biology and Biogeochemistry Program for collecting and maintaining the Ocean Color Data sets, and the United States Geological Survey NASQAN program for their excellent river data sets. This work was funded by NASA grant XXXXXXX to C.E. Del Castillo. Ship time was also provided by NSF grant XXXXX to Rodney Powel (LUMCON).

\section{References}

Blough, N. V., O. C. Zafiriou, and J. Bonilla, Optical Absorption spectra of waters from the Orinoco River outflow: Terrestrial input of colored organic matter to the Caribbean. J. Geophys. Res., 98(C2), 2271-2278, 1993.

Blough, N.V., and R. Del Vecchio. 2002. Chromophoric DOM in the Coastal Environmnet. In: Biochemistry of Marine Dissolved Organic Matter . D.S. Nasell and C.A. Carlson eds. Academic Press. 774 pp

Carder, K. L., F. R. Chen, Z. P. Lee, ., S. K. Hawes, D. Kamy-Kowski, Semianalytic moderateresolution imaging spectrometer algorithms for chlorophyll a and absorption with bio-optical domains based on nitrate depletion temperatures, J. Geophys. Res., 104, 5403-5421, 1999.

Del Castillo, C. E., P. G. Coble, J. López, J. Morel, and J. E. Corredor, Analysis of the optical properties of the Orinoco River plume by absorption andfFluorescence spectroscopy, Mar. Chem., 66, 35-51, 1999.

Del Castillo, C. E., F. Gilbes, P. G. Coble, and F. E. Müller-Karger,On the dispersal of riverine Colored Dissolved Organic Matter (CDOM) over the West Florida Shelf. Limnol. Oceanogr., 45(6), 1425-1432, 2000.

Del Castillo, C. E., P. G. Coble, R. N. Conmy, F. E. Müller-Karger, L. Vanderbloemen, and G. Vargo,Multispectral in-situ measurements of dissolved organic matter and chlorophyll fluorescence in seawater: Documenting the intrusion of the Mississippi River plume in the West Florida Shelf, Limnol. Oceanogr.,. 46(7), 1836-1843, 2001.

Del Castillo, C.E. Remote Sensing of Colored Dissolved Organic Matter in Coastal Environments. In Remote Sensing of Aquatic Coastal Environments R. M. Miller, C. E. Del Castillo, and B. McKee, Editors. Kluwer Academic Publishers. 2005. 
Del Vecchio R. and N.V. Blough ( 2002) Photobleaching of chromophoric dissolved organic matter in natural waters: kinetics and modeling. Mar. Chem., 78, 231-253

Degens, E. T., S. Kempe, J. E. Richey. Eds. Biogeochemistry of Major World Rivers. John Wiley \& Sons. New York.356 pp., 1991.D’Sa, E. and R. L. Miller, Bio-optical properties in waters influenced by the Mississippi River during low flow Conditions, Remote Sensing of Environment, 84(4), 538-549, 2003.

D’Sa E. J., R.L. Miller and C.E. Del Castillo. (2006). Bio-optical properties and ocean color algorithms for coastal waters influenced by the Mississippi River during a cold front passage. Appl. Optics. In press.

Hoge, F.E., M.E. Williams, R.N. Swift, J.K. Yungel, and A. Vodacek. (1995). Satellite retrieval of the absorption coefficient of chromophoric dissolved organic matter in continental margins. $J$. Geophys. Res., 100, 28,847-24,854

Hoge, F.E., C.W. Wright, P.E. Lyon, R.N. Swift, and J.K. Yungel. (2001). Inherent optical properties imagery of the western North Atlantic Ocean: Horizontal spatial variability of the upper mixed layer. J. Geophys. Res., 106, 31,129-31,140

Johannessen S.C., W.L. Miller, and J.J. Cullen. (2003). Calculation of UV attenuation and colored dissolved organic matter absorption spectra from measurements of ocean color. $J$. Geophys. Res., 108.C9 3301, doi:10.1029/2000JC00541

Kahru, M. and B.G. Mitchell. (2001). Seasonal and non-seasonal satellite-derived chlorophyll and dissolved organic matter concentrations in the California Current. J. Geophys. Res., 106, 2517-2529.

Lee, Z., K. L. Carder, S. K. Hawes, R. G. Steward, T. G. Peacock, and C. O. Davis,Model for the interpretation of hyperspectral remote-sensing reflectance. Appl. Opt. 33: 5721-5732, 1994.

Mantoura, R. F. C. and E. M. S. Woodward,Conservative behavior of riverine dissolved organic carbon in the Severn estuary: Chemical and geochemical implications, Geochim. Cosmochim. Acta, 47, 1923-1309, 1983.

Muller, J. L. and R. W. Austin, Ocean optics protocols for SeaWiFS validation, revision 1. In S.B. Hooker, and E.R. Firestone (Eds.), NASA Tech. Memo,104566. 25. Greenbelt, MD NASA Goddard Space Flight Center, 67 pp, 1995.

Qian, J. and K. Mopper, Automated high-performance, high-temperature combustion total organic carbon analyzer, Anal. Chem., 68, 3090-3097, 1996. 
Siegel, D.A., S. Maritorena, N.B. Nelson, D.A. Hansell, and M. Lorenzi-Kayser. (2002). Global ocean distribution and dynamics of colored and detrital organic materials. J. of Geophys. Res., 107:c12, 3228,doi:10.1029/2001JC000965

Siegel, D. A., S. Maritorena, N. B. Nelson, M. J. Behrenfeld, and C. R. McClain,Colored dissolved organic matter and its influence on the satellite-based characterization of the ocean biosphere, Geophys. Res. Lett., 32, L20605, DOI:10.1029, 2005.

Siegel, D. A. and A. F. Michaels, Quantification of non-algal light attenuation in the Sargasso Sea: Implications for biogeochemistry and remote sensing, Deep-Sea Res. II, 43, 321-345, 1996.

Stallard, R. F., L. Koehnken, and M. J. Johnsson (1990). Weathering processes and the composition ofinorganic material transported through the Orinoco river system, Venezuela and Colombia. From: Weibezahn, F.H., Haymara, A. and M.W. Lewis (1990). The Orinoco River as an ecosystem. Caracas: Universidad Simon Bolivar.

Vodaceck A., N. V. Blough, M. D. DeGramdpre, E. T. Peltzer, and R. K. Nelson, Seasonla variation of CDOM and DOC in the Middle Atlantic Bight: Terrestrial inputs and photooxidation, Limnol. Oceanogr. 42, 674-686, 1997.

Van Heukelem, L., A. J. Lewitus, T. M. Kana, and N. E. Kraft, Improved separations of phytoplankton pigments using temperature-controlled high performance liquid chromatography, Mar. Ecol. Prog. Ser., 114, 303-313, 1994.

Wright, V.M. 2005. The Seasonal Dynamics of Colored Dissolved Organic Matter in the Mississippi River Plume and Northern Gulf of Mexico. [M.S. thesis]: University of Southern Mississippi. 68p.

Zar, J.H. Biostatistical Analysis. Third Edition, 1996 Prentice Hall, New Jersey 662 pp.

\section{Figure Captions}

Figure 1. Flow chart showing the method and rational of this project. Boxes represent empirical relationship, plain text represent the outputs of these relationships. $\mathrm{R}$ is the remote sensing reflectance ratio used in this study, and $\mathrm{DOC}_{\mathrm{p}}$ and $\mathrm{DOC}_{0}$ are the concentrations of $\mathrm{DOC}$ in the river plume and river end-member respectively.

Figure 2. Relationship between [DOC] and ag $412 \mathrm{~nm}$ (A), and ag $412 \mathrm{~nm}$ and salinity (B). Data shown here come from surface samples collected during 5 cruises to coastal waters of Louisiana between 2000 and 2005 .

Figure 3. SeaWiFS image of the study site showing the area sampled during the Acadiana cruises, and the sampling station at Forth Jackson, LA. This RGB image is a monthly composite of scenes collected during Month year. 
Figure 4. Relationship between ag 412 and $R$. The least square linear regressions for the Acadiana I data only (dashed line), and all the data (solid line) are $R=-1.04(\operatorname{ag} 412)+2.51$, $\mathrm{r}^{2}=0.94, \mathrm{n}=10$, and $R=-1.08(\operatorname{ag} 412)+2.47, \mathrm{r}^{2}=0.60, \mathrm{n}=21$ respectively. The statistics for the comparison between slopes are: critical $t_{0.05(2), 27}=2.052$, calculated $t=0.119$. For the elevations, critical $t_{0.05(2), 28}=2.048$, calculated $t=1.132$.

Figure 5A. Modeled salinity vs. monthly river flow averaged from daily measurements collected by the USGS at St. Francisvile, LA. The least square linear regression equation is: salinity = $8.33 \times 10^{-7}$ (river flow $1 \mathrm{~s}^{-1}$ ) $+33, \mathrm{r}^{2} 0.71, \mathrm{n}=82$. Figure $6 \mathrm{~B}$, comparison between measured and modeled flow. The slope of the regression is 1 , and the elevation is $422,2021 \mathrm{~s}^{-1}, \mathrm{r}^{2}=0.70, \mathrm{n}=$ 82.

Figure 6A. Temporal variability in modeled and measured DOC transport by the Mississippi River. The data includes the period between January 1998 and December, 2005. Figure 6B. Modeled vs. measured DOC transport. The line represents the 1 to 1 relationship. The regression coefficient for the least squares regression line was $0.70, \mathrm{n}=67$. 
Figure 1

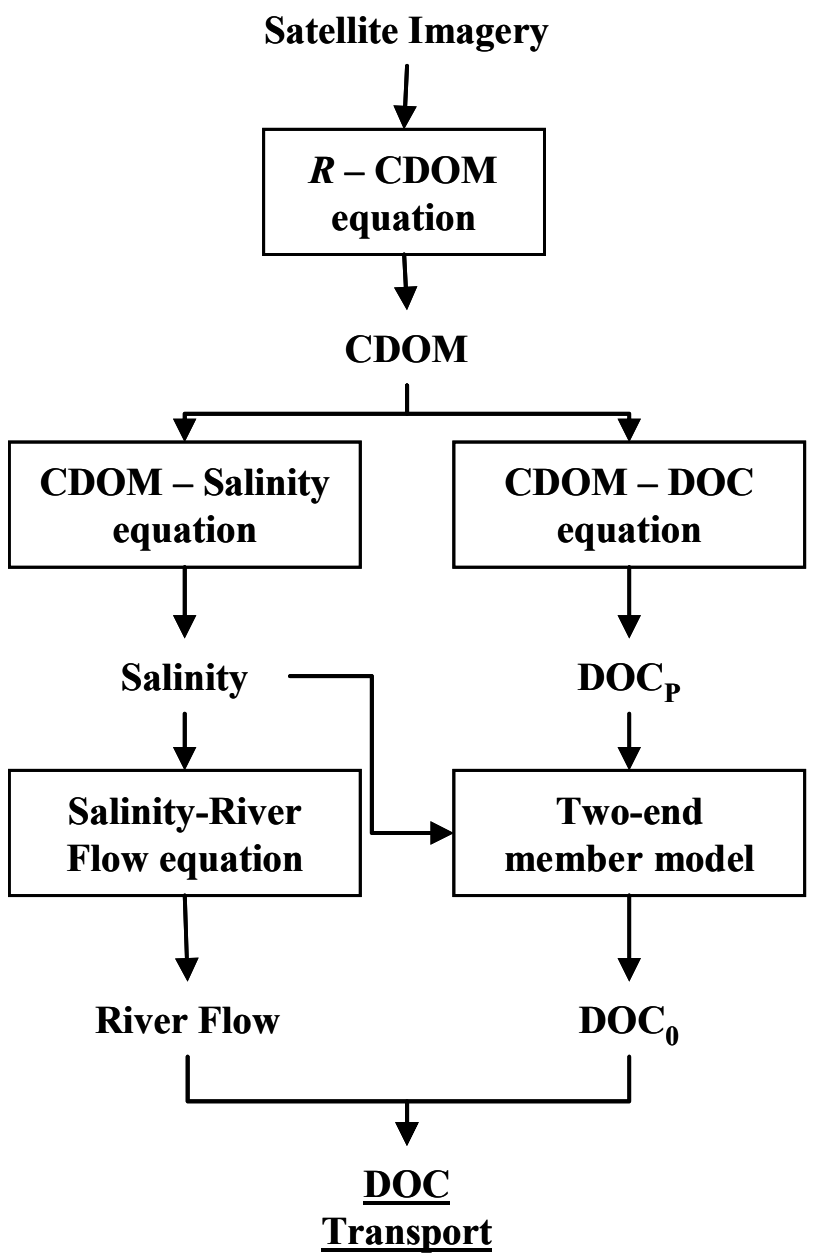

$-13-$

RELEASED - Printed documents may be obsolete; validate prior to use. 
Figure 2
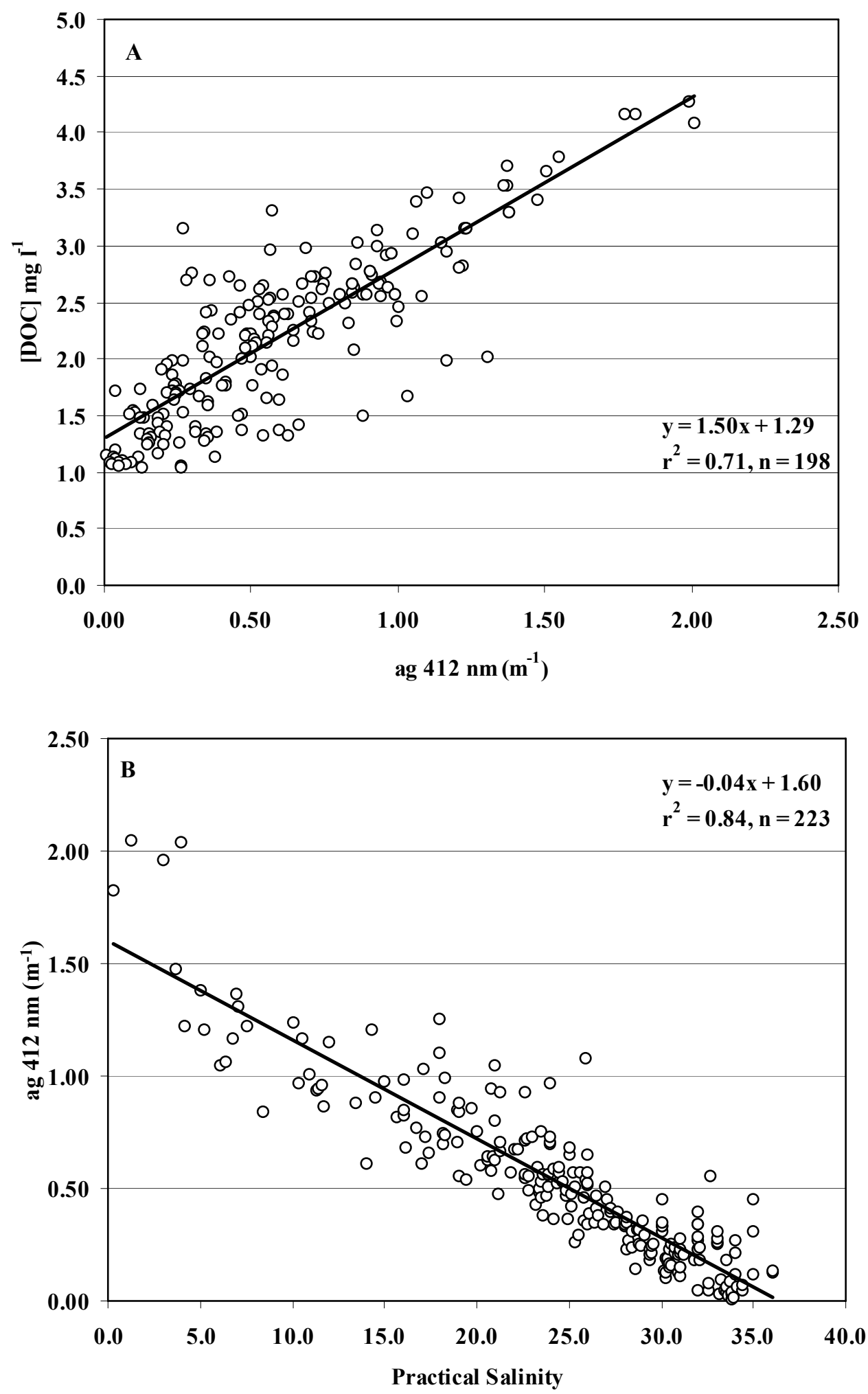

$-14-$ 
Figure 3.

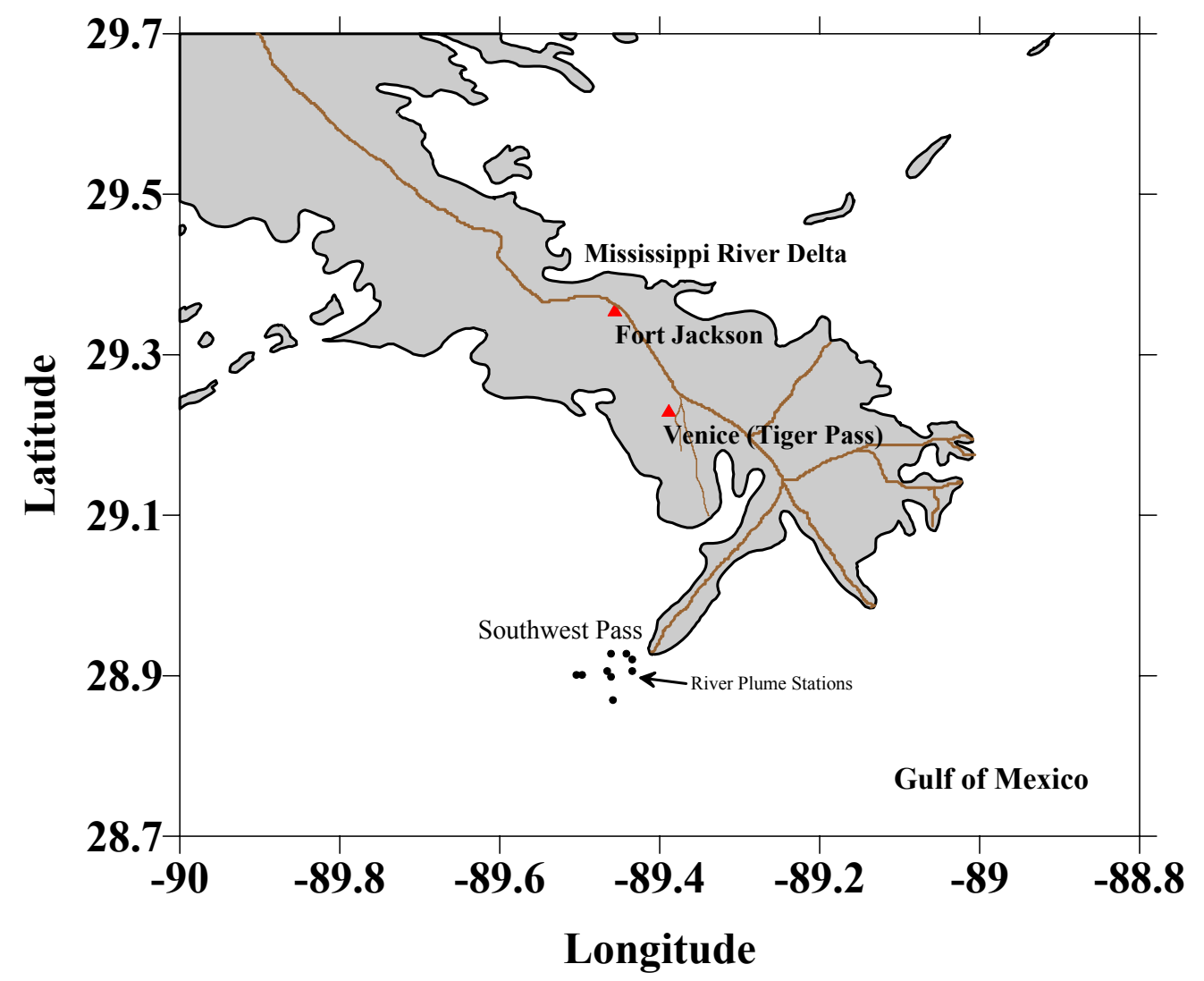

$-15-$ 
Figure 4

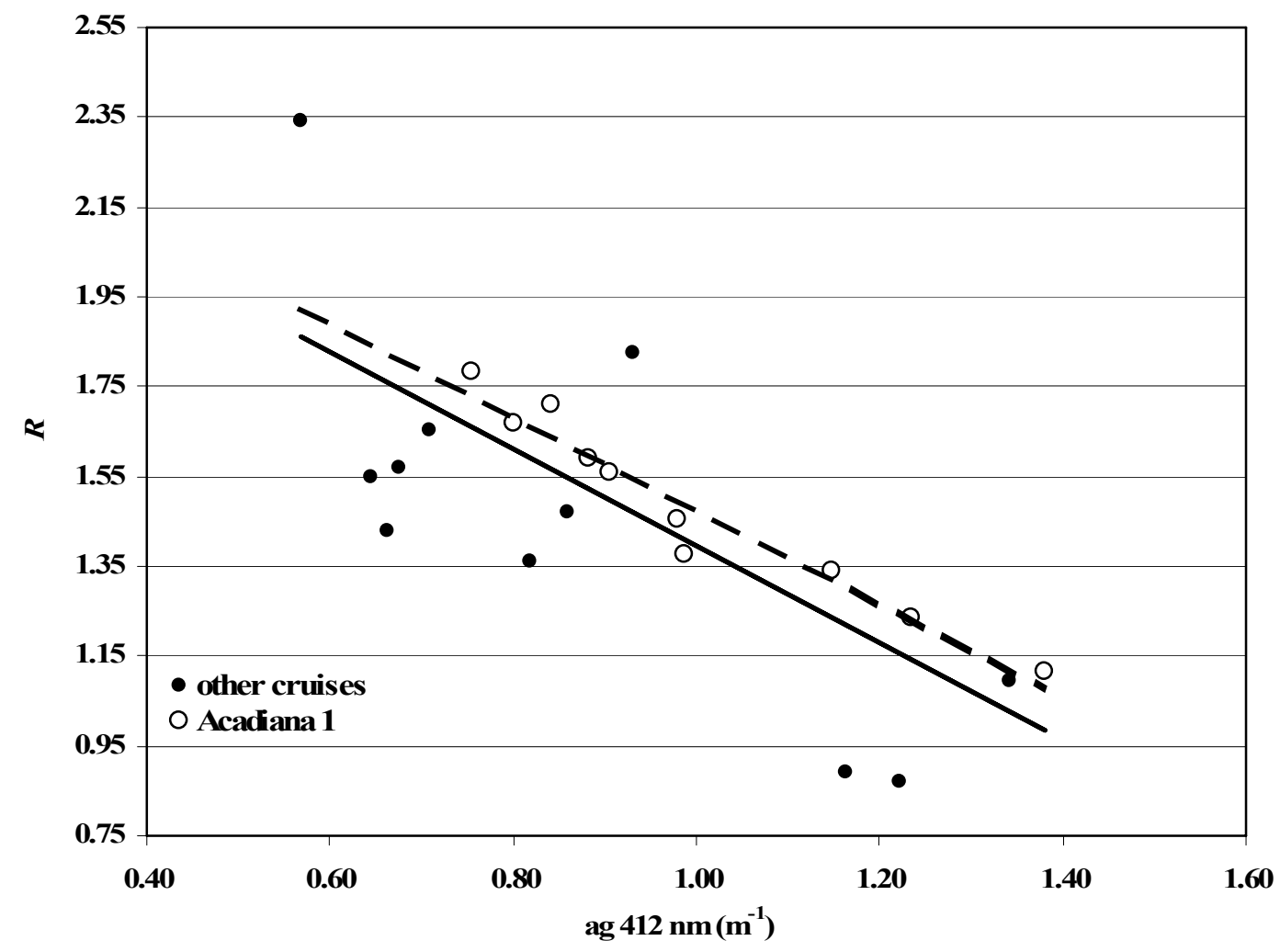

$-16-$

RELEASED - Printed documents may be obsolete; validate prior to use. 
Figure 5
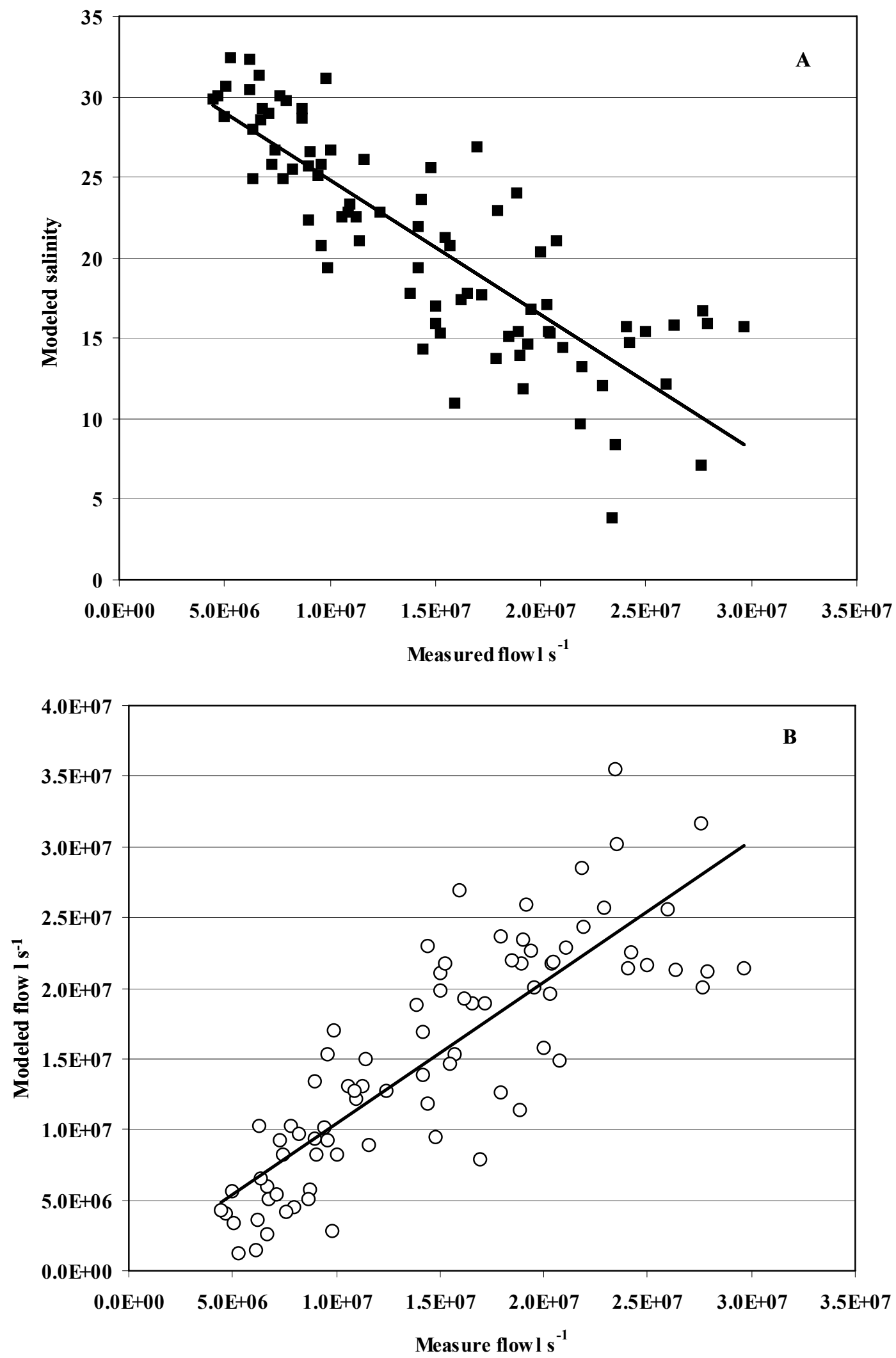

$-17-$

RELEASED - Printed documents may be obsolete; validate prior to use. 
Figure 6
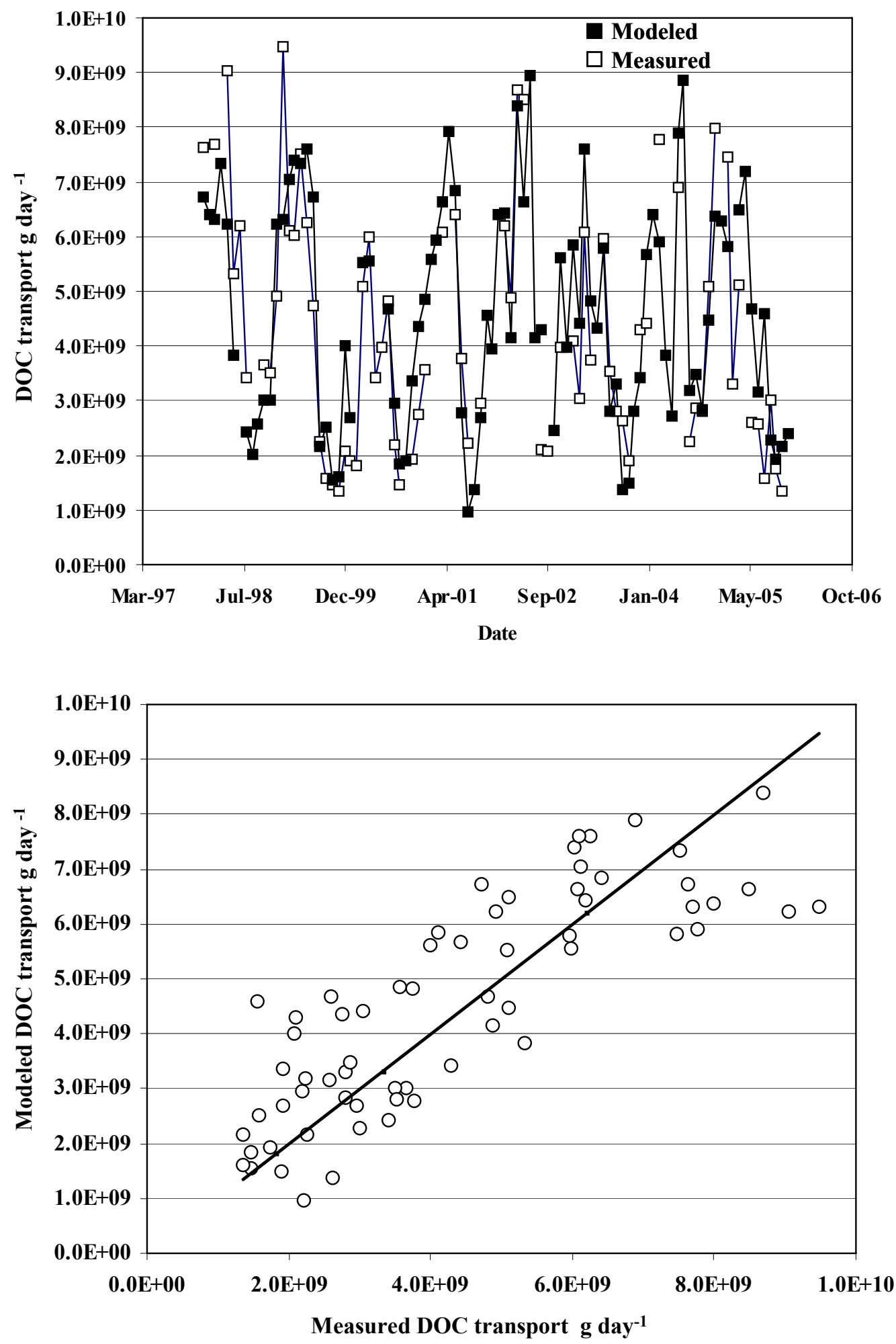

$-18-$

RELEASED - Printed documents may be obsolete; validate prior to use. 